\title{
Management of social virtuum as a singular space-time continuum and its logistics: phenomenological divergence and convergence
}

\author{
Julia Kharchenko ${ }^{{ }^{*}}$, Sergej Kharchenko ${ }^{1}$, Svetlana Lavrinenko', and Olga Antipova ${ }^{1}$ \\ ${ }^{1}$ National Aviation University, Kosmonavta Komarova ave, 1, 03058, Kyiv, Ukraine
}

\begin{abstract}
The analysis of the dynamic infrastructure of the social virtuum as an increasing variety of social spheres and dimensions has been conducted. It was shown that to build its logistics in accordance with the cyclical, linear and rhizome changes that from radically re-equip is quite problematic; and therefore, society as a virtuum was explained largely as an abstraction, which, however, can exist as a material formation in space and time. On this basis, the main purpose of the research was conceptualization of the primary mechanisms for managing the social virtuum as a singular space-time continuum based on phenomenological divergence and convergence, as well as an analysis of its conditional logistics and the complexity of its virtual topology. The phenomenological method as the theoretical basis of this research showed the social virtuum as an interconnected unity of various principles of existence in its economic, political, cultural, civilizational, virtual, spiritual dimensions and as a set of events experienced by individuals as continuous primary experiences. The divergent and convergent approaches depicted social processes in continuous interaction, providing progressive movement, stable development and functioning of all existing subsystems of a complex society.
\end{abstract}

\section{Introduction}

Socio-philosophical science seeks to explain not only the essence and origin of social virtuum as a complex structure, but also to present all its architectonics as a kind of unity, integrity, singularity. This is necessary, first of all, in order to: continuously analyze the state of society as a whole organism; to predict the prospects for its development; understand the causes of social entropy; identify the prerequisites for institutional, political, economic, scientific, cultural, spiritual progress or regression; to develop constructive approaches for solving key tasks; introduce the most effective mechanisms for managing society as a complex system. Recently, however, an increase in entropy can be observed at the level of global and regional processes.

\footnotetext{
* Corresponding author: kharchenkojv@gmail.com
} 
With the above-mentioned points in mind, S. Radziyevska and I. Us concluded that, on the one hand, regionalization leads to deglobalization, since integration at the regional level improves the strengthening of unity at the local level, and the weakening of unity at the global level. However, on the other hand, the formation of a regional state dismantles the group of nation-states and strengthens the global unity. The key point is that regionalization leads to globalization, to the reduction of the number of nation states in the world, but under certain condition, namely - when the formed regional grouping reaches the state of full integration and through a political treaty becomes a regional state instead of the totality of nation-states, on the basis of which it was created. Finally, they argued that those processes of regionalization that are currently shaping the world economy are actually limited by the concluded free trade agreements, established customs unions and common markets. So, they, on the one hand, increase the overall efficiency of economic processes and enhance regional integration, but, on the other hand, do not substantially bring the world closer to political unity. In summary, the strengthening of regionalization processes, that is, the increased segregation of the established and developed regional organizations, weakens the global cohesion of the world. Moreover, if the above-mentioned processes result in the political union - a regional state, conditions are created to unite these new complex regional states and thus move us closer to the time of formation of a single planetary state. It is important to underline, that the processes of regionalization, on the one hand, by the time they are completed and the political union is formed - a new regional state - are contributing to a single planetary state formation, and, on the other hand, they are weakening the unity of the world. But at the same time the unification of new regional powers strengthens the global cohesion of the world, given that such dynamics of regionalization development leads to a reduction of the number of states in the world through their unification. Until the process of regionalization reaches the establishment of the new, more economically powerful regional state, it aims at reducing the unity of the world. But by completing this process, regionalization creates the conditions for a leapfrog to strengthen the unity of the world by uniting new powerful regional states. However, such powerful new regional states may not be interested in losing their independence and even decide to segregate or join some of the similar powerful new states to form separate unions. So, the above-mentioned detailed explanation helps to understand the logic behind the multipolar global world formation as opposed to the unipolar world maintaining [1].

The infrastructure of the social virtuum, which is formed in a whirlpool of an increasing variety of social spheres and dimensions, is unusually dynamic, therefore, to build its logistics in accordance with the cyclical, linear and rhizome changes that from time to time radically re-equip it is quite problematic.

Society as a virtuum, therefore, is largely an abstraction, which, however, can exist as a material formation in space and time. The time factor (historical time) plays a key role in the social space-time continuum, since it allows to observe the holistic architectonics of society from the existing scientific and historical experience. Space-time as a physical model is a theoretical construct, which is actualized in philosophical science and is considered in the form of a space-time continuum, which, in turn, has various images and faces. This model is used when considering culture, politics, the spiritual sphere, and the sphere of art and many other dimensions of public life. They form the logistics of social virtuum.

The significance of history in the formation of social virtuum is great. Time allows accumulating valuable experience in cognition and management of the life world in the context of a combination of its three inalienable factors: past, present and future. The life world is to a greater extent a spiritual sphere of human existence, since it is filled with special meanings. Recently, however, modern science is trying to explain the spiritual principles purely technically. For example, attempts are being made to model 
consciousness, to connect consciousness with the vital activity of biological organisms. The body of the machine should be as much as possible practical and optimal in management. The technical brain, in turn, becomes more complicated and improved and becomes more and more functional. However, such experiments are not always successful, and the human phenomenon remains unique so far. Replacing its consciousness is still problematic.

P. Wang and F. Si notice that a neural network with the number of hidden neurons equal to training samples is impractical, which will bring huge difficulties to the training of neural network. Therefore, increasing the number of hidden layers can solve this contradictory problem to some extent [2]. In the social virtuum, the brain-consciousness dyad is actualized (that is, the technical side prevails), but society as an ontic-ontological construction is based on higher spiritual meanings produced by the collective consciousness. Dynamic artificial neural networks form an ersatz system (we propose to call it imaginary society), but the logistic component of such a model is also quite interesting. Of course, artificial intelligence, rapidly learning, creates new opportunities in virtual life. But they are still limited.

P. Wang and F. Si analyzed the dynamic artificial neural networks applied into thermal nonlinear modeling and discuss the applicability of DNN, RNN, LSTM and DHNN. In their view, the above models are test on theoretical and experimental examples which contain thermal complex nonlinear system. Simulation results show that in almost all the cases examined, the LSTM and DHNN based on LSTM has shown superior modeling accuracy and has also shown more robustness as compared to the other identification models. Thus, DHNN based on LSTM can be regarded as a general identification network that can be applied to the identification of a wide class of nonlinear dynamic systems [2].

Although the term "logistics" is associated primarily with the economic, business and industrial spheres of people's lives, it is increasingly used in philosophy as an abstraction. Through this abstraction, the engineering of ideas is carried out, mechanisms are developed that facilitate the design of new approaches to life and ways of thinking, information flows are managed, and these flows are transported in virtual space. Consequently, the term "logistics" expands the range of its meanings and requires reflection in philosophical ontology and social philosophy.

The key objective of this study is the conceptualization of the primary mechanisms for managing the social virtuum as a singular space-time continuum based on phenomenological divergence and convergence, as well as an analysis of its conditional logistics.

\section{Materials and Methods}

We admitted that society can be considered as a singularity. Society is a collection of artifacts created by an intelligent person, and its analogue has not yet been discovered. These artifacts reflect the best qualities of people as creators (there are, of course, negative aspects of their activities). The singularity itself, as has already been shown, is presented as something primary as a kind of the beginning of the process. Based on the available scientific experience, the singularity of social virtuum as an integral organism, the unification of all individuals is also primary so far, that is, it is a unique phenomenon. The archetype is the primary mental structure; consciousness and soul are also phenomenal, as they represent the uniqueness of each person.

The essence of the phenomenon of social virtuum as a singular space-time continuum, in our opinion, can be most productively covered using the principles of phenomenology and socio-philosophical ontology.

The phenomenological method allows us to think of the social virtuum as an interconnected unity of various principles of existence in its economic, political, cultural, 
civilizational, virtual, spiritual dimensions and as a set of events experienced by individuals as continuous primary experiences. The combination of these experiments turns events into symbolic and significant milestones of history, which actualizes the role of the space-time characteristics of social virtuum. At first glance, divergent histories such as the history of the Universe and the history of mankind become convergent in the process of further cognition of the world. The key problem remains the problem of their synchronization.

The phenomenological method contributes to the reflection of consciousness on "life in the social space-time". The consistent application of phenomenological reductions leads to a generalization of the key sides of various models of singularity and the identification of signs of the singularity of the social virtuum, up to its a priori foundations, found as the foundation of everything that is true for our consciousness. "Reality in society" and "reality outside of society" are also divergent, since the formation of social virtuum as artificial nature in natural nature contributed to the "separation" of human from this nature, the implementation of attempts to overcome the effect of physical laws. On the other hand, it is impossible to completely separate from nature precisely because the material infrastructure of society is subject to these laws. However, the phenomenological method allows us to trace the transcendental facets of the social virtuum.

Phenomenological divergence and convergence encompass phenomena and concepts that designate a species (or variety), a particular quality, features of the activity, existence and development in time of objects of any kind. These terms penetrated into the discourse of socio-philosophical ontology from biology. Divergence is the opposite of convergence. In the social space, divergence is associated with an increase in the qualitative diversity of political, economic, cultural, ideological and other manifestations, and the complexity of its virtual topology. Divergent and convergent processes are in continuous interaction, providing progressive movement, stable development and functioning of all existing subsystems of a complex society.

The term "divergence" is interpreted as a divergence of attributes among related organisms in the process of their evolution, or the disintegration of the initially unified ecological community into several independent new ones. The term "convergence" means rapprochement. When considering the phenomenon of social virtuum, it is interpreted as the acquisition in the course of development of similar traits and functions by unrelated (distant) social organisms due to their adaptation to the same conditions.

The ideation of the architectonics of the life world as a singular social virtuum allows us to consider it at the transcendental level as a "pure entity" that is "above nature" or "outside of nature". The social virtuum is presented both as a "pure essence" and as a combination of objects of experience. Social virtuum as a "pure essence" strives for its quintessence - to completely overcome the influence of physics and biology on the architectonics of the space-time continuum, which would allow a person to survive beyond anything, or to overcome the limits as such. It is the phenomenological "construction" that allows us to think such an opportunity at the level of imagination or fantasy.

Ideation and phenomenological reduction are the basis for all transcendental methods that can be used in the analysis of the primary mechanisms for controlling the social virtuum as a singular space-time continuum. Phenomenological reduction provides research on the primary image of social virtuum as a singularity (the return of society as a being to its being).

Phenomenological reduction allows freeing from the natural setting of collective and individual consciousness to know only external objects, temporary and changeable. In combination with the transcendental methodology, it raises the collective and individual consciousness to the level of ontic-ontological meanings, and directs the creative perception of the social life world as a complex virtuum, as a singularity with internal infinite diversity. 


\section{Results}

"Logistics of social virtuum" is, relatively speaking, a continuous process of planning, distribution, control, provision, exchange, receipt of material things, as well as information flows of a certain quality and in a certain quantity from a source (or manufacturer) to a consumer. Such a product is also aimed at satisfying people's spiritual needs, depending on the level of spiritual culture, spiritual development and moral imperatives of society and an individual. This definition covers absolutely all special concepts that are part of the functional area of society as a complex system. It reflects the need for a single effective management of this system as a singularity. Logistics of social virtuum provides a comprehensive result due to internal and external integration of key elements of the system and spheres of life.

The logistics of social virtuum also provides for the distribution of large and small flows of people, which today we can observe in a globalized world. Thus, O. Kuzmin, M. Bublyk, A. Shakhno, O. Korolenko and H. Lashkun emphasize that the innovative development of human capital is a major factor in building a model of sustainable economic development in the context of globalization transformations, as it is formed through investment in human beings. The effectiveness of investment is determined by the level of development of productive abilities of the individual, capable of innovative work, creativity, creativity. The growth of the role of human capital in the conditions of sustainable development of the innovative economy necessitates the use of new approaches to its assessment, formation, and development. An important role in the reproduction of human capital is played by the state, which pursues regulatory policy using regulatory acts. The formation of an effective organizational and economic mechanism of state regulation of human capital development is a priority task that will create appropriate conditions for increasing the quality of human capital, its innovative potential, which will enhance the competitiveness of the national economy. Further research will be to develop strategic directions and mechanisms for the development of innovative human capital, using the foreign experience of developed countries [3].

Logistics also contributes to the organization of work in small and large groups, taking into account the use of information technology.

E. Lavrov, P. Paderno, E. Burkov, A. Volosiuk and Vu Duc Lung focus on participants and performers - cognitive scientists, working groups. In their view, the defining aspects of this phase are: the form of expert information presentation; the polling procedure. The most convenient for formalization and processing are quantitative point estimates. Less convenient are interval estimates. This is due to the fact that the burden of formalizing the opinions rests with the experts themselves, albeit receiving assistance from information extraction specialists. However, cognitologists together with analysts have to develop a system of criteria to be used by experts. This requires: compile a complete (but not redundant) list of criteria, determine the structure of relationships between the criteria, assess the relative importance of the criteria (usually for this one needs to involve experts), develop an adequate scale for each criterion and interpret its values [4]. Consequently, the key tools of logistics processes are efficiency, management, transportation, energy costs.

The logistics of social virtuum also includes the implementation of convergent technologies: this includes information and communication technologies, biotechnology, nanotechnology and cognitive technology.

For example, today interdisciplinary research is being conducted, the basis of which is information technology, which, in turn, involves the use of software in the management of complex and local systems, as well as in the study of environmental processes, which makes it possible to optimize risks in various sectors of life. 
A. Iatsyshyn, V. Artemchuk, I. Kameneva, V. Kovach and O. Popov have shown that the software was developed to solve problems of visual analysis of ecological status dynamics of territorial systems and to determine boundaries of sustainability of individual territories. They presented new forms of presentation of monitoring data of anthropogenic loads and risks to analyze the dynamics of anthropogenic impact and to determine the boundaries of stability of local systems. Monitoring reflects ecological situation dynamics in the space of informative features. They stress that it is important to improve skills of professionals particularly in ministries, business and organizational staff responsible for decision-making to reduce negative impact on environment and to train future professionals in this area. Only a few higher education institutions offer training courses for stuff who are working in the sphere of management, ecology and nature use. But it is not paid much attention on training to use managerial decision support software. The main areas of professional development of the specialists responsible for management are: conducting training seminars at the ministries, institutions and departments interested in implementing the developed systems; scientific and methodological support and advisory assistance in the process of implementation of the developed software; development and improvement of educational and methodological support for postgraduate students and trainees of advanced training of specialists responsible for management decisions in energy, environmental and related fields [5].

In turn, the convergence of planetary and locally planetary infrastructures is no less important. Modern convergent technologies provide a combination of tools for predicting the development trends of these infrastructures and managing various events and risks associated with natural phenomena and disasters.

Similar tools are used in hydrological modeling and landscape hydrology in the study of flash floods and other natural phenomena. The problem of flash floods is becoming relevant today in connection with tectonic changes in nature (for example, global warming). L. Kuksina and V. Golosov emphasize that although flash floods are one of the most dangerous natural events on Earth and bring significant damage to people and economical infrastructure their study is only at the start point. There is even no uniform term for that event. Study of flash floods is very complicated task due to small spatial and temporal scale of the event and their origin in remote mountain regions difficult for access and monitoring organization. The main factors of flash floods formation could be divided into three groups - hydrological and meteorological, lythological and geomorphological and anthropogenic ones. Their analysis demonstrates the main reason of flash floods origin is high intensity rainfall formed in mountain regions. The basis for flash floods forecast is precipitation prediction with accounting of relief promoting rapid flow concentration in channel. Hydrological modeling and landscape hydrology have great prospects in flash floods studies [6]. General planetary and locally planetary processes can also be considered in conjunction with the social environment in solving the problems of "global" modeling (in the construction of society as an integral infrastructure). General planetary and locally planetary processes always give rise to sudden fluctuations and they are sources of instability and uncertainty.

M. Bolgov rightly pointed out that in contemporary hydrology, new probabilistic models to improve the existing conclusions and results are developed, and approaches are offered allowing solving new tasks associated mainly with the change in conditions of how hydrological phenomena and processes are formed for different reasons. Initial data limitation and changes occurring in natural and social environments, despite the significant progress of tasks of "global" modeling do not call off and probably won't call off in the future the need to develop probabilistic ideas and approaches. Only based on probabilistic approaches, it's possible to forecast runoff distribution taking into account the key sources of uncertainty in solving contemporary hydrology's problems [7]. 
The synchronization of sources of uncertainty is indeed partly possible provided that the efforts of many technical, mathematical, and space sciences are combined that can simulate complex processes and assess the nearest probable risks. However, in the field of forecasting, effective resolution of problems also depends on modern philosophical science that can look into the distant future and talk about global consequences.

A. Plugin, O. Pluhin, D. Plugin and O. Borziak offer their own solutions: based on the provisions of colloid chemistry and physic-chemical mechanics of disperse systems and materials, a hypothesis has been put forward about the influence of electrical phenomena on geological processes and global catastrophes; it is assumed that one of the moving forces of geological processes and global catastrophes is the excess negative electric charge of the Earth cyclically accumulated as a result of macropolarization phenomena. It is concluded that the increase in the number of global disasters in recent decades has been influenced by space rocket launches. This effect is due to the fact that as a result of the combustion of rocket fuel, rocket take-off, a significant amount of electric charge is transferred, and it is divided between the earth and the upper atmosphere. A further increase in the number of launches and mass of rockets may lead to an increase in the number of catastrophic events. The prevention of catastrophic events is possible based on an analysis of the causes of the accumulation of excess charges, the development and implementation of ways to prevent such accumulation. The authors conclude that this research did not receive any specific grant from funding agencies in public, commercial, or not-for-profit sectors [8].

Social philosophy and ontology are just able to "remove" the problem from the narrowness of financial institutions, bureaucratic obstacles, the views of the layman, because they raise it to the level of existence in three time axes - in the past (memory and experience), present (experience and understanding) and future (expectations and dreams). They also evaluate from a moral point of view "desire to act", "totality of actions" and "consequences of actions".

As a result, it is possible to demonstrate several models for the development of the logistics of social virtuum as a singular space-time continuum (see Fig. 1, Fig. 2 and Fig. 3).

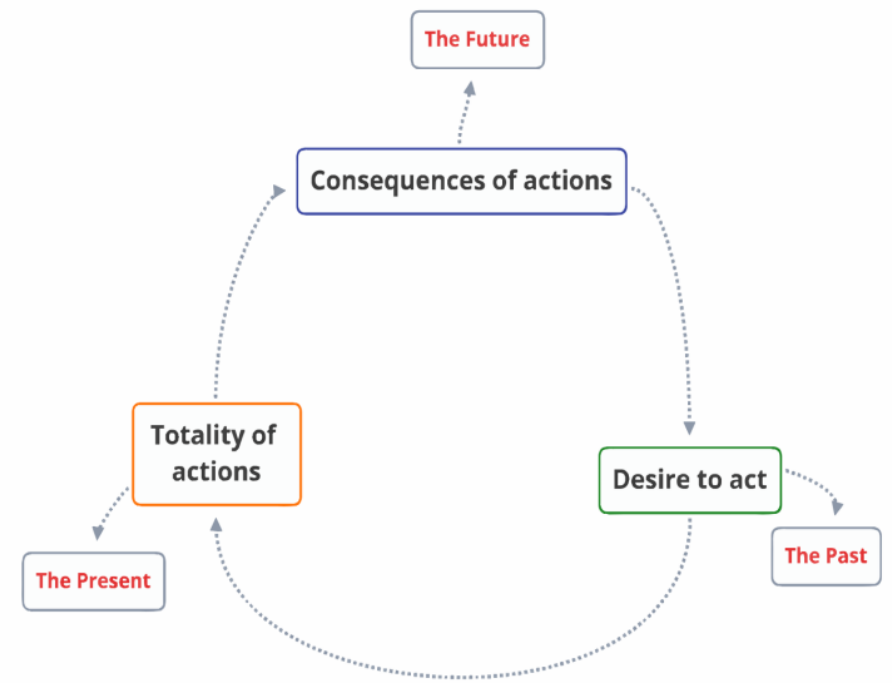

Fig. 1. Human as the creator in the space-time continuum of social virtuum. 


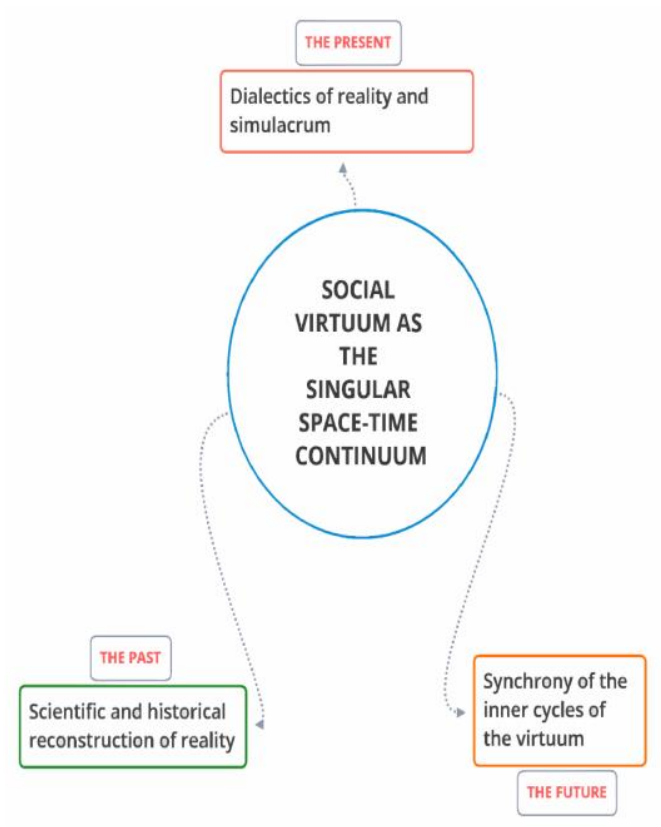

Fig. 2. Social virtuum as a moving global technosphere.

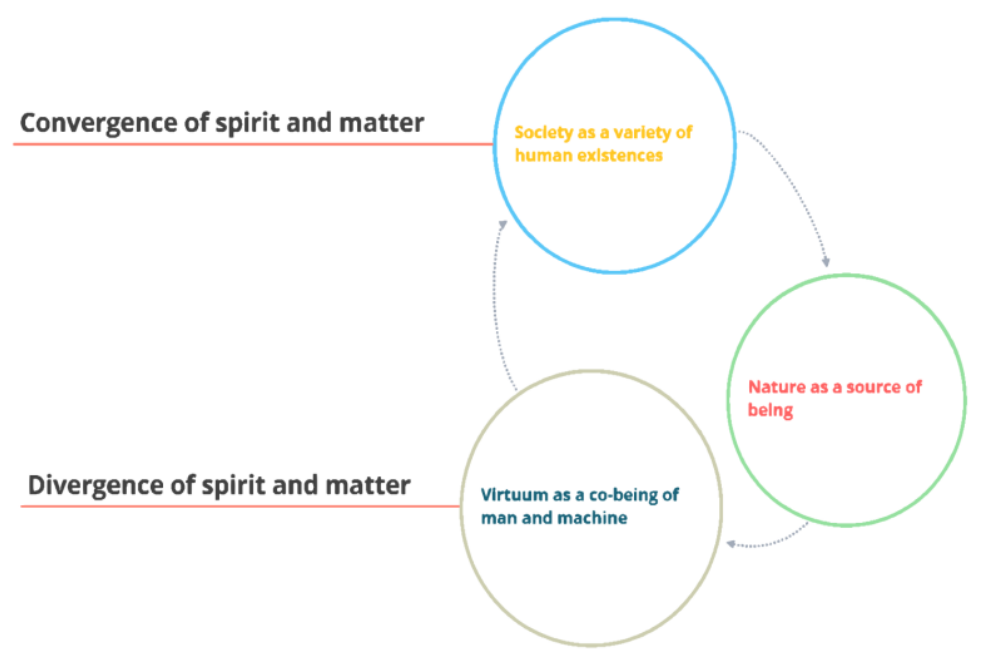

Fig. 3. Phenomenological divergence and convergence in the integrated logistics of social singularity: the interaction of natural, artificial and simulated realities.

\section{Discussion}

The social virtuum "expands" and "contracts". The social virtuum "is expanding" "outside itself" and "inside itself". "Outside itself" it becomes planetary, linking the cosmos, consciousness and technical science. "Inside itself" it creates a virtual illusion of itself, its copy, a semblance of reality. The social virtuum "shrinks" to its own limits, and to the limits of each of its images and versions. Natural wildlife creates a singularity within itself. 
The existence of society as an all-planet virtuum is so far isolated, which allows us to speak of a singularity. Many micro-social areas within the virtuum do not always synchronize harmoniously in this general construction.

Philosophy considers the term "singularity" as the whole universe, concentrated at a tiny point, as all the substance of the Universe, as life, with its awareness, significance and feelings. "The singularity of the space-time continuum of social virtuum" means the singularity of social virtuum as a unique all-planetary event, creature and phenomenon. Planet Earth is a space, the logistics of which depend on the capabilities and means created by people, as well as on their understanding of various time models.

Unlike cosmological, gravitational, mathematical, technological, biological singularities, the singularity of the social virtuum represents the state of being as the life world of a person in which matter and consciousness dialectically coexist. On the one hand, the space-time continuum of society is consistent with the principles of development: $a$ cosmological singularity that describes the state of the Universe in the first instant of the Big Bang, which is characterized by the presence of infinite values of the density and temperature of matter; gravitational singularity as a point located in space-time through which it is not possible to evenly draw a geodesic line, which makes the values (energy density or scalar curvature) that describe the gravitational field infinite or undefined; mathematical singularity as a point at which the desire for infinity is characteristic of a mathematical function, or the function has other irregularities in behavior; technological singularity as a factor of the future, taking into account progress in science and technology, the application of bio- and nanotechnology, in which artificial intelligence as an original substrate will allow a new look at a person and a machine, consciousness and soul; biological singularity as a bifurcation point in the evolutionary process.

On the other hand, the space-time continuum of society projects into reality its opposite images - "eternity" and "nothing", which are especially important for a person's spiritual perception of everyday life. The singularity is not only not material, but also not proven; therefore, its application is purely hypothetical. Mathematical, biological, and technological singularities have clear parameters if the objects of research are sufficiently material, but abstractions that are not reducible to a real object are more common. The social virtuum is simultaneously a material and non-material singularity.

D. Zhmurko concluded that time acts as a qualitative characteristic of space. A space in which there are no processes of fundamental interaction is eternity. A point (a multitude, a system) that comes out of the "custody" of the point that generated it becomes its negation. It forms a new space (point, multitude, system), becoming a negation of the starting point. The duration of the system's existence gives it the property of eternity: while the Universe expands, it is eternal with respect to the objects that are located or which it generates. In a system that is at rest, a mechanism opposite to expansion is triggered; all its structural connections are intensified. Functioning only "for oneself" in the future leads to the death of this system. Any movement sooner or later comes into a state of rest, "gets stuck" in it, and then a new impetus occurs due to internal contradictions, and so on to infinity. It is known that a state of rest is the absence of movement. This definition can be refuted as follows: an object attracted by another, much larger object, moves along with it along its path. In this case, there are not two objects of different mass and quality, but a planet or another space object in (on) which the existing objects are at rest, i.e., the parameters of its frequency, phase and amplitude are the same (reduced to some kind of equilibrium state). To exist in relations with such objects means to be in harmony with the environment [9]. The author does not break such concepts as the Universe and morality and considers the development of the Universe and the development of society to be convergent processes.

In his opinion, if we consider time in the social aspect, the category of "time" as a criterion of universality contradicts the category of "morality". So, history shows how 
society moved from a slave system to capitalism (a society of the highest degree of injustice). With the advent of the concept of "time" the concept of "management" appears [9]. Management is not always fair; inefficient management can create rhizome tendencies in society.

D. Zhmurko rightly showed that in the modern understanding of the categories of space and time, the processes connecting them are heterogeneous and do not meet the principles of formal logic [9]. Historical time has reflected various painful examples of inefficient management of society and the tragic consequences of ill-conceived actions and decisions in various areas of public life.

No less painful is the historical experience gained in the field of science. The scientific approach involves a deep assessment of the likely risks and errors when using technical means, a special responsibility in professional activities.

We give an example of developments that demonstrate the effectiveness of new control systems. O. Savytskyi, M. Tymoshenko, O. Hramm and S. Romanov proved that the analysis of soft sensors using in the automated control of various industrial processes shows their versatility and benefits. The use of soft sensors is often a more viable alternative to hardware, as very often physical sensors have to operate in extreme conditions, are quite expensive and need frequent replacement. It is advisable to use soft sensors in the case of a large number of similar mechanisms operating in approximately the same conditions. Measuring certain performance of one mechanism, you can roughly judge the situation as a whole. Unlike sensors made from various material substances, soft sensors have a different basis. By definition, "soft sensors" are based on the use of software and the calculation of regulated process parameters. Thus, the environmental friendliness of their use is not in doubt. At the same time, it is not necessary to check such sensors for the content of harmful substances and hazardous emissions during their operation. At the end of their life cycle, one does not have to worry about compulsory utilization [10]. Automated control systems, mathematical methods and models really show their versatility and advantages almost everywhere. However, despite this, human, as a spiritual and moral being, is the quintessence of a complex social virtuum in all its manifestations, and it is human who "humanizes" the machine and nature.

\section{Conclusion}

The key goal of this study was to analyze the primary mechanisms for managing the social virtuum. Modern society is becoming an increasingly complex construction. Its structure includes not only nature as such and the artificial nature in all its diversity, but also a virtual environment in the form of a global technosphere.

On the one hand, these three "natures" are divergent, since the Universe is governed by physical laws, society by man, and the virtual world by machine. Synchronization of control mechanisms through the convergence of the three "natures" is possible if a person as a biological, social, spiritual being is a mediator structure, connecting them in essence and in meaning. Improving historically and practically its cognitive programs and methods, it transforms "around-itself-being". As a result of this, society becomes a virtuum, in which matter, spirit and technology are combined.

Social virtuum as a singular space-time continuum exists as a unit, generating many bifurcation points in the evolutionary process of its self-development. Micro-social areas within the whole virtuum do not change in time and space synchronously, which leads to divergent processes of repulsion, rejection, inconsistency. However, over time, the system comes into equilibrium. 
The phenomenological divergence and convergence demonstrated the abstract nature of the conditional logistics of the social virtuum. Such logistics involves engineering ideas, designing new approaches to life and ways of thinking, transporting information flows.

\section{References}

1. S. Radziyevska, I. Us, E3S Web of Conferences, 166, 13016 (2020) https://www.e3sconferences.org/articles/e3sconf/pdf/2020/26/e3sconf_icsf2020_13016.pdf

2. P. Wang, F. Si, E3S Web of Conferences, 162, 01007 (2020) https://www.e3sconferences.org/articles/e3sconf/pdf/2020/22/e3sconf_icpeme2020_01007.pdf

3. O. Kuzmin, M. Bublyk, A. Shakhno, O. Korolenko, H. Lashkun, E3S Web of Conferences, 166, $13011 \quad$ (2020) https://www.e3sconferences.org/articles/e3sconf/pdf/2020/26/e3sconf_icsf2020_13011.pdf

4. E. Lavrov, P. Paderno, E. Burkov, A. Volosiuk, V.D. Lung, E3S Web of Conferences, 166, $11002 \quad$ (2020) https://www.e3sconferences.org/articles/e3sconf/pdf/2020/26/e3sconf_icsf2020_11002.pdf

5. And. Iatsyshyn, An. Iatsyshyn, V. Artemchuk, I. Kameneva, V. Kovach and O. Popov, E3S Web of Conferences, 166, 01001 (2020) https://www.e3sconferences.org/articles/e3sconf/pdf/2020/26/e3sconf_icsf2020_01001.pdf

6. L. Kuksina and V. Golosov, E3S Web of Conferences, 163. 02005 (2020) https://www.e3s-

conferences.org/articles/e3sconf/pdf/2020/23/e3sconf_vc2020_02005.pdf

7. M. Bolgov, E3S Web of Conferences, 163, 06001 (2020). https://www.e3sconferences.org/articles/e3sconf/pdf/2020/23/e3sconf_vc2020_06001.pdf

8. Ark. Plugin, And. Plugin, Ol. Pluhin, Dm. Plugin and Olga Borziak, E3S Web of Conferences, $\quad \mathbf{1 6 6}, \quad 02001 \quad$ (2020) https://www.e3sconferences.org/articles/e3sconf/pdf/2020/26/e3sconf_icsf2020_02001.pdf

9. D. Zhmurko, Political mathematical electronic scientific journal of the Kuban State Agrarian University, 05(89), (2013) http://ej.kubagro.ru/2013/05/pdf/74.pdf

10. O. Savytskyi, M. Tymoshenko, O. Hramm, S. Romanov, E3S Web of Conferences, 166, 05003 conferences.org/articles/e3sconf/pdf/2020/26/e3sconf_icsf2020_05003.pdf 